\title{
A Statistical Tool to Generate Potential Future Climate Scenarios for Hydrology Applications
}

\author{
Antonio-Juan Collados-Lara $\mathbb{D}^{\mathbb{D}},{ }^{1}$ David Pulido-Velazquez, ${ }^{1}$ and Eulogio Pardo-Igúzquiza ${ }^{2}$ \\ ${ }^{1}$ Spanish Geological Survey, Urb. Alcázar del Genil 4, Bajo, 18006 Granada, Spain \\ ${ }^{2}$ Spanish Geological Survey, Ríos Rosas 23, 28003 Madrid, Spain \\ Correspondence should be addressed to Antonio-Juan Collados-Lara; ajcollados@gmail.com
}

Received 13 March 2020; Revised 18 May 2020; Accepted 22 May 2020; Published 29 June 2020

Academic Editor: Francisco J. Alcalá

Copyright ( $) 2020$ Antonio-Juan Collados-Lara et al. This is an open access article distributed under the Creative Commons Attribution License, which permits unrestricted use, distribution, and reproduction in any medium, provided the original work is properly cited.

\begin{abstract}
Global warming associated with greenhouse emissions will modify the availability of water resources in the future. Methodologies and tools to assess the impacts of climate change are useful for policy making. In this work, a new tool to generate potential future climate scenarios in a water resources system from historical and regional climate models' information has been developed. The GROUNDS tool allows generation of the future series of precipitation, temperature (minimum, mean, and maximum), and potential evapotranspiration. It is a valuable tool for assessing the impacts of climate change in hydrological applications since these variables play a significant role in the water cycle, and it can be applicable to any case study. The tool uses different approaches and statistical correction techniques to generate individual local projections and ensembles of them. The non-equifeasible ensembles are created by combining the individual projections whose control or corrected control simulation has a better fit to the historical series in terms of basic and droughts statistics. In this work, the tool is presented, and the methodology implemented is described. It is also applied to a case study to illustrate how the tool works. The tool was previously tested in different typologies of water resources systems that cover different spatial scales (river basin, aquifer, mountain range, and country), obtaining satisfactory results. The local future scenarios can be propagated through appropriate hydrological models to study the impacts on other variables (e.g., aquifer recharge, chloride concentration in coastal aquifers, streamflow, snow cover area, and snow depth). The tool is also useful in quantifying the uncertainties of the future scenarios by combining them with stochastic weather generators.
\end{abstract}

\section{Introduction}

Adaptation to climate change (CC) is one of the greatest challenges that humans will face in the coming decades $[1,2]$. This is related to greenhouse gas emissions, mainly anthropogenic carbon dioxide emissions [3]. CC is accepted by the scientific community and most of the society [4]. In the last decades, unprecedented changes (increment in temperature $(T)$ of the atmosphere and oceans, changes in the spatiotemporal variability of precipitation $(P)$ (including more extreme events), reduction of ice, snow, and groundwater levels, and rises in sea level) have been observed $[2,5]$. The Fifth Assessment Report (AR5) of the Intergovernmental Panel on Climate Change (IPCC) [3] includes four future trajectories of anthropogenic carbon dioxide emissions for the twenty-first century, called representative concentration pathways (RCPs). From these trajectories, different climate institutes and organizations develop regional climate models (RCMs) whose data are coordinated and collected by the World Climate Research Program (WCRP) through the CORDEX project [6].

Despite the multiple uncertainties related to RCMs, they provide valuable information that could be used for further evaluation and policy making $[7,8]$. Water systems, which are essential for life, are and will be one of the most affected by CC. In general, CC will modify the spatiotemporal variability of climatic variables. Among them, $P$ and $T$ are the main variables that govern the hydrological cycle $[9,10]$. 
Decision makers should have enough information about how these systems will change in the future to design appropriate adaption strategies. For this reason, local scenarios of CC have to be generated from the climatic model simulations to analyse impacts on water resources (WR) systems.

Potential local future scenarios of $P$ and $T$ can be used to propagate impacts of CC on other hydrological variables in different WR systems, such as river basin [11, 12], aquifer $[13,14]$, and mountain range $[15,16]$. RCMs include control and future simulations of $P$ and $T$ among other climatic variables. However, the RCM simulations cannot be used directly due to the high amount of uncertainties $[17,18]$. The statistics of the control series can differ a lot from the statistics provided by historical or observed time series for the considered baseline period. Therefore, the time series provided by the RCMs must be corrected $[19,20]$ before using them for other applications, generating local series for the specific WR system.

Different statistical correction techniques can be used, such as correction of first- and second-order moments or regression approaches. They have different degrees of complexity and can have different accuracy. These correction techniques can be applied under two conceptual approaches: bias correction and delta change [21, 22]. RCMs and/or correction techniques can be evaluated comparing the control or corrected control simulation series with the historical information. Equifeasible and non-equifeasible (defined by giving more weight to the more reliable projections) ensembles of individual predictions can be employed to obtain more robust predictions [23]. The generation of potential local scenarios, through the correction of the RCMs simulations, involves several nontrivial tasks (selection of the RCMs, RCPs, and reference and future periods and/or level of global warming and application of the correction approaches and techniques) which should be addressed before the propagation of the impacts to hydrological variables. Therefore, tools and methodologies that automate the process are valuable for hydrological applications. Some tools are available to generate local future climate scenarios. Most of them are focused on the bias correction approach using different correction techniques mainly based on the statistical distribution of data (e.g., qmap [24] and CMhyd [25]). However, as far as we know, the application of different correction techniques under the delta change approach requires generating scenarios for specific future horizons and/or level of global warming that have not been included in a tool. On the other hand, these tools do not include the option of creating non-equifeasible ensembles of projections with different weights depending on the reliability of RCMs and correction techniques attending to some basic and/or drought statistics. In this work, these possibilities are incorporated.

We present a new tool to generate potential future CC scenarios for hydrology applications. The GROUNDS (GeneRation of pOtential fUture CC sceNarios for hyDrology applicationS) tool generates distributed future monthly series of $P, T$ (maximum, minimum, and mean) and potential evapotranspiration (ETP) using as inputs historical series and RCM simulations. This tool integrates some methodological aspects studied in previous works $[12,26]$ (generation of individual projections and creation of ensembles of them) and new potentialities (identification of the period of the RCM to be used for a specific local warming and generation of ETP projections) into an intuitive command-line interface applicable to any case study. The main advantages of the tool are (1) its applicability to any case study and series of data (RCMs, RCPs, simulation periods, etc.), (2) it only requires historical data and RCM simulations to generate the potential future scenarios, (3) it allows using different approaches and statistical correction techniques, and (4) it generates individual local projections and ensembles, including equifeasible and non-equifeasible approaches considering the approximation to historical basic and drought statistics.

The GROUNDS tool allows different possibilities of generating future scenarios and can be used for different purposes depending on the interest of the users:

- Specific level of local warming vs. a specific future period: users can be interested in studying the availability of WR under different RCMs or know how the system will change according to a defined warming.

- Individual projections or ensembles of projections: based on multicriteria analyses [8], they allow to select the individual projections that provide the best approximation to some selected basic statistics (first, second, and/or third moment) or drought statistics (frequency, intensity, magnitude, and duration), which are assessed by applying the Run Theory to the Standard Precipitation Index (SPI) series for the studied variable. They also allow to define ensembles scenarios by combining the selected individual projections. The first option is indicated to quantify uncertainty by using several RCMs and the second to obtain more robust prediction of mean values.

- Different variables according to the preferences of the user: $P$, maximum, mean, and minimum $T$ and ETP.

These future scenarios are also useful to assess impacts of $\mathrm{CC}$ on the availability of WR in a system by propagating the climate inputs to other variables with appropriate hydrological models.

\section{Description of the Tool: Data, Methods, and Example Results}

Figure 1 shows a flow chart of the methodology implemented in the tool GROUNDS to generate potential climate scenarios to assess impacts on WR systems. The tool, which includes four subroutines, was written entirely in Fortran 90 and can be executed under a command-line interface. The description of the inputs, parameters, subroutines, and outputs of the tool are shown in Figure 2.

The target is to use historical long enough monthly series of $P$ and $T$ (maximum, minimum, and mean) to generate future potential local climatic scenarios of them. It also includes a subroutine to calculate ETP. Note that monthly 


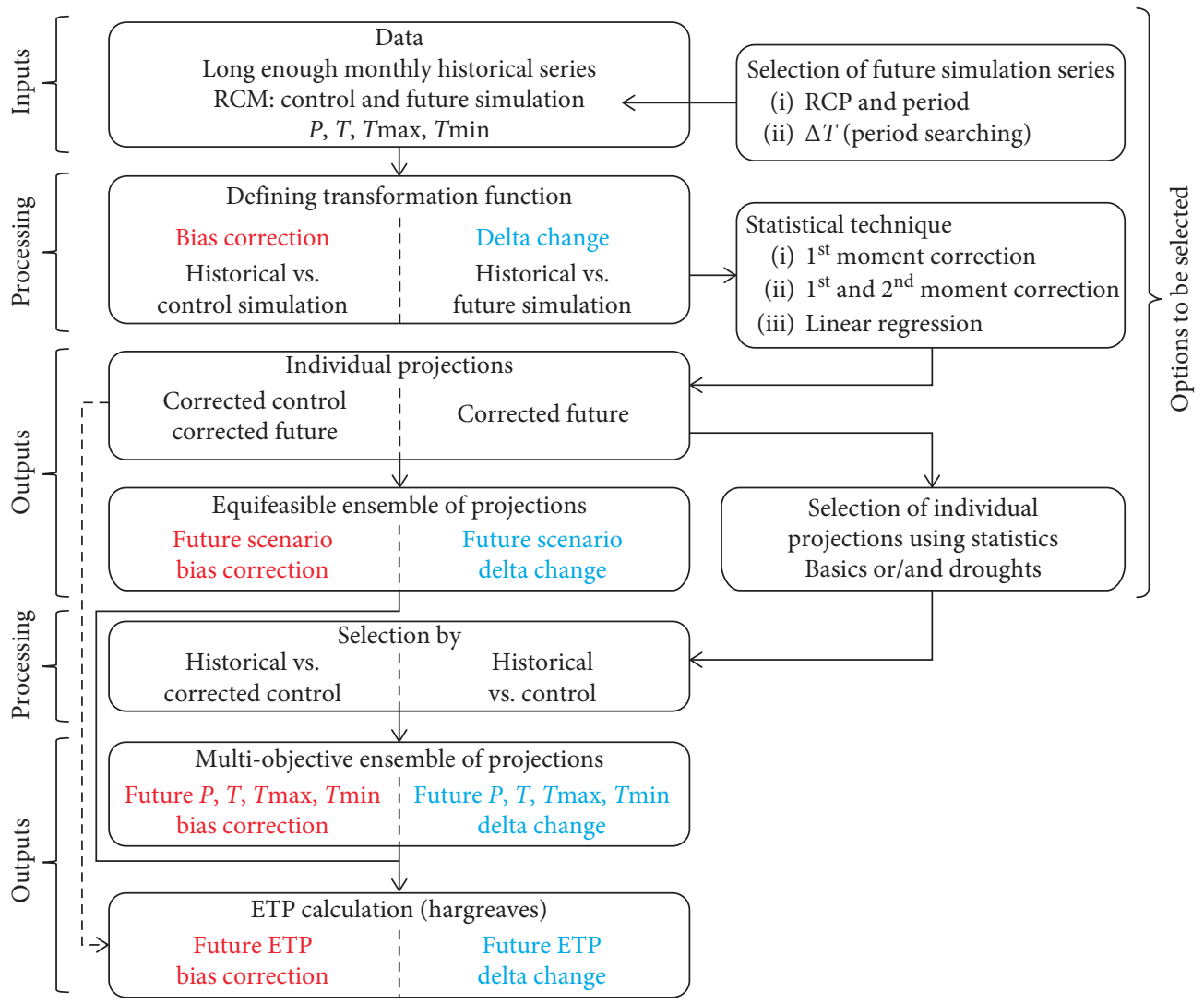

FIgURE 1: Flow chart of the assessment performed with the tool.

series should be complete (without gaps) and the quality of the data should be assessed by the user to ensure that they are representative of the climatology of the study area. It can be applied to point series that correspond to gauges measurements (in which gaps have to be previously completed) or to distributed fields, previously estimated on a grid with an appropriate method. Note that, in any case, those series have to cover the adopted historical reference period. The individual local series are generated using the subroutine inpro.exe that requires as inputs the monthly series of the climatic variables and the parameters $L, N$, and $M$ which represent the length of the series (number of months), the numbers of points or stations considered in the case study, and the code (from 1 to the number of RCMs considered) that represents the RCM to be used, respectively. The historical series should be long enough in order to fulfil the assumption of stationarity of their statistics. If the series are not long enough, they might include drought or wet periods that modify the statistics of the series, making them not representative of the baseline period. A period of at least 30 years is recommended $[12,27]$. With respect to the selection of the future projections, the tool allows two possibilities: (1) to fix a future horizon (specific period of time) or (2) to use an increment in mean $T$ (e.g., local warming of $1^{\circ} \mathrm{C}$ ) with respect to the value for the adopted historical reference period. The second procedure can be done by using the subroutine search.exe. It requires as input data the future simulation series of $T$ for each RCM considered for the whole period available, the adopted longitude (e.g., 30 years) for the reference period, and the mean increment of $T$. This subroutine identifies a future period with a longitude equal to the historical (e.g., 30 years) in which the fixed local warming with respect to the historical is reached. The subroutine calculates a moving average considering an aggregation window equal to the considered length of the future simulation series and compares these values with the simulation series for the reference period. These increments of $T$ represent different levels of local warming. The $T$ and $P$ series for the identified period will be used to perform the statistical correction of the series to generate the local scenarios that fulfil the adopted warming criteria.

In this work, we have applied it to a case study, used as an example to illustrate how the tool generates future series of climatic variables. The historical series employed correspond to a point (located in the province of Granada, south Spain) (longitude: -4.0877 , latitude: 37.3789 , and elevation: $1016 \mathrm{~m}$ a.s.l.) of the grid used by the Spain02 v04 project [28]. This project includes $P$ and $T$ interpolated for continental Spain. The CC information was obtained from RCMs from the CORDEX project [6]. We selected two RCMs (CCLM4-8-17 nested to the CNRM-CM5 and WRF331F nested to IPSLCM5A-MR) and the most pessimist scenario (RCP8.5). Both project use the same grid for Spain (spatial resolution of $12.5 \mathrm{~km}$ ).

Using the subroutine search.exe, we calculated a 30-year moving average that allows us to identify when a specific warming is reached. Figure 3 shows the increment of temperature with respect to the reference period 


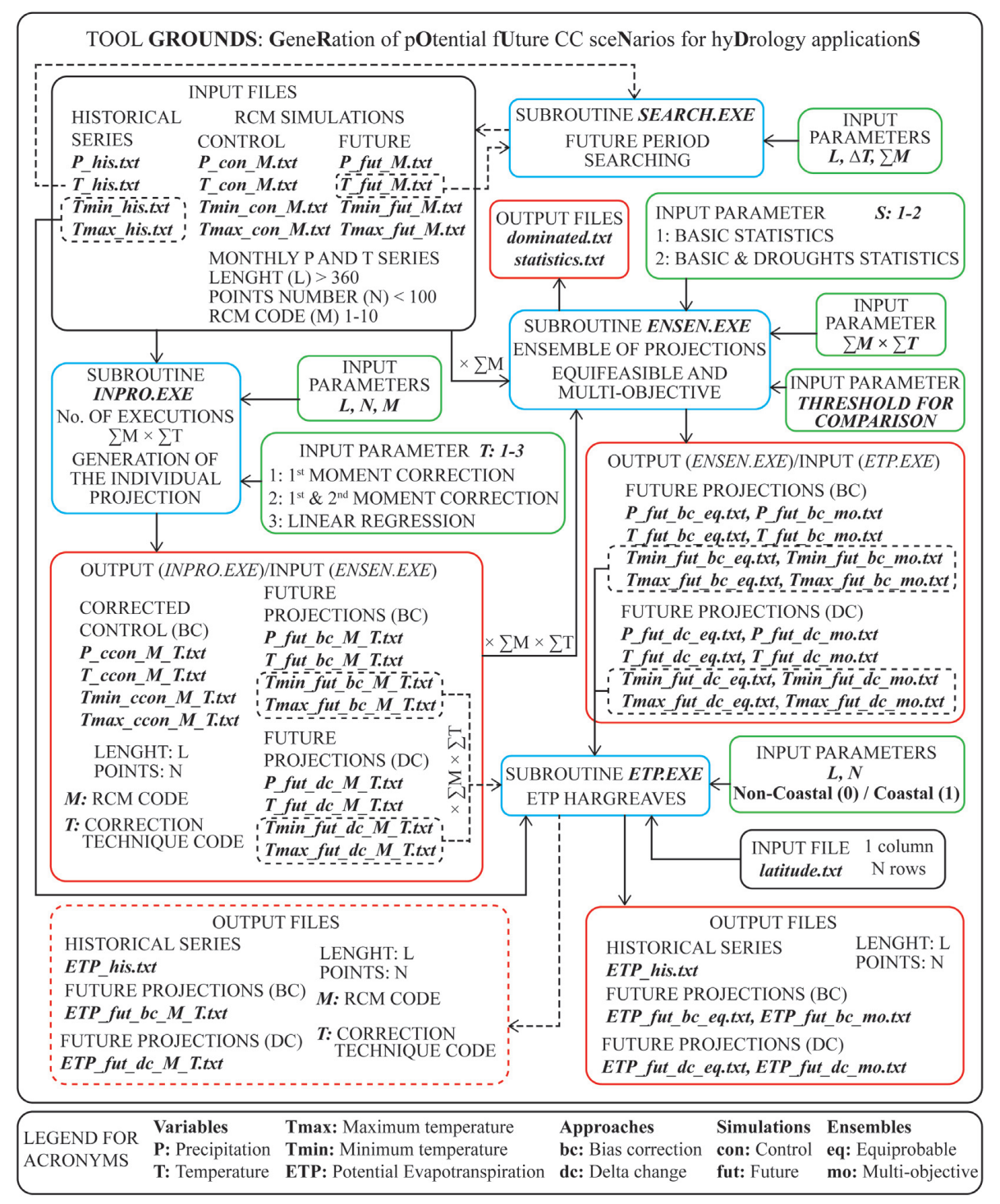

FIgURE 2: Flow chart of the GROUNDS tool subroutines.

(1971-2000) for the two RCMs considered and different future periods.

In this study, we selected the same future period for the generation of scenarios (2071-2100). Note that if a specific local warming is selected, different periods (periods in which the constraint is fulfilled) should be considered for each RCM. For example, in our case, a local warming of $4^{\circ} \mathrm{C}$ is reached for 2071-2100 in the case of CCLM4-8-17 nested to CNRM-CM5 and for 2064-2093 in the case of WRF331F nested to IPSL-CM5A-MR (see Figure 3).

The subroutine inpro.exe uses two conceptual approaches (bias correction and delta change) and three correction techniques, defined by a transformation function, to generate future potential scenarios (see Figure 1). The bias correction approach defines a transformation function to modify the control simulation series to another one whose statistics are more similar to the historical ones. The same function is applied to the future simulation series assuming that the bias between the historical data and the RCM simulations will be maintained invariant in the future
$[29,30]$. On the other hand, the delta change approach assumes that the RCMs provide good approximation of the relative changes between future and control simulations, and those changes are applied to the historical series to generate future projections $[22,31]$. Note that delta change approach does not correct the RCM simulations; it only modifies the historical series to obtain the future series. From the point of view of the tool, the main difference between bias correction and delta change is that the first generates corrected control series for each combination of correction technique and RCM. The tool allows using three different correction techniques: first moment correction (code 1), first and second moment correction (code 2), and linear regression (code 3) (see Figure 2). These techniques, unlike quantile mapping techniques, do not assume a specific statistical distribution of data. The different correction techniques are applied at monthly scale. In the first moment correction, the transformation function is performed considering only the mean values, while the first and second moment correction technique considers mean and standard deviation. The 


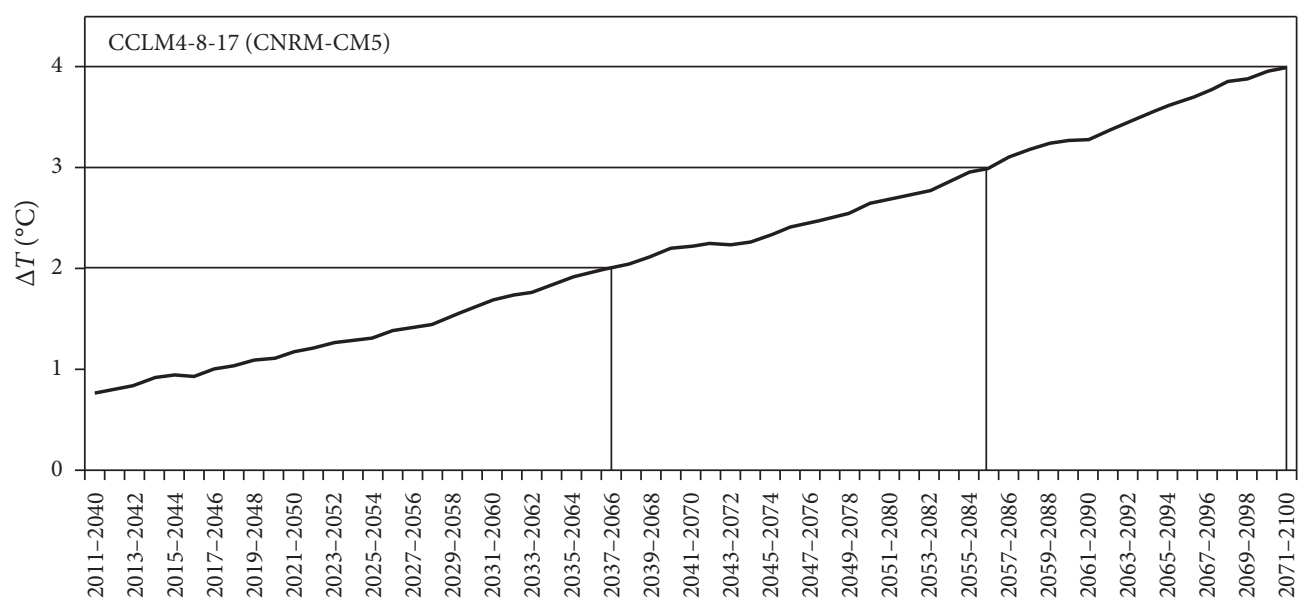

(a)

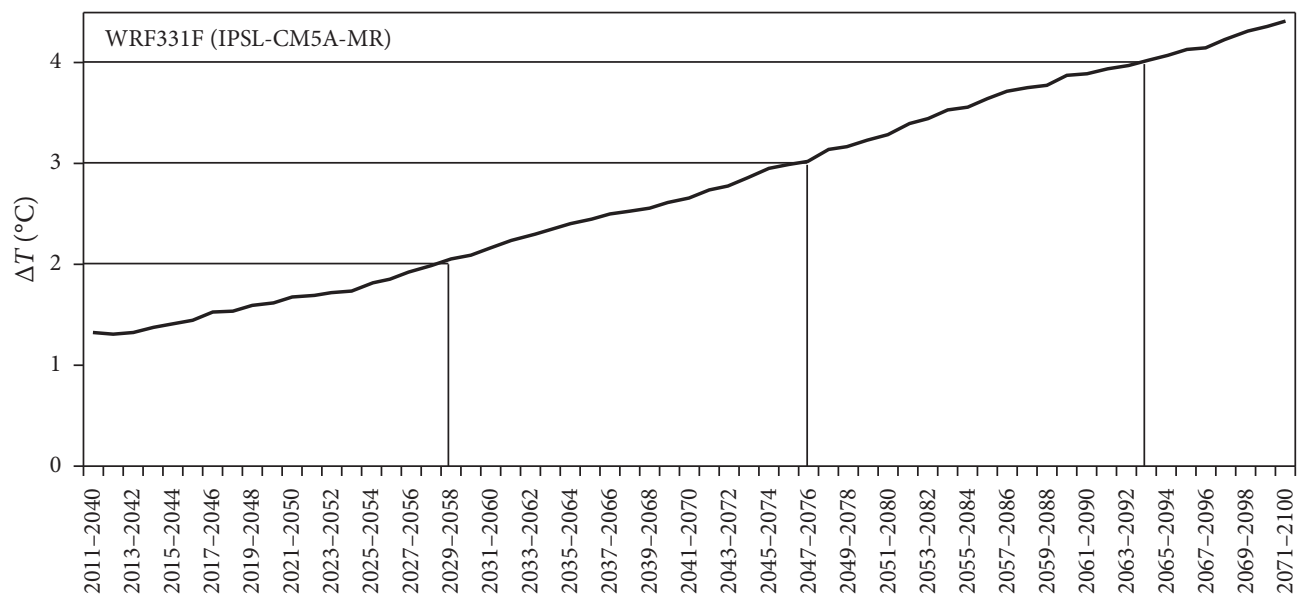

(b)

FIGURE 3: Local warming reached with respect to the reference period (1971-2000) for the (a) RCM CCLM4-8-17 nested to GCM CNRMCM5 and (b) RCM WRF331F nested to GCM IPSL-CM5A-MR.

transformation function in the linear regression is elaborated through fitting a regression model between historical data and control simulation in the case of the bias correction approach and between the control simulation and future simulation in the case of the delta change approach. Note that the tool employs the best linear fit and provides the correlation coefficient $\left(R^{2}\right)$ of it. The user should decide if its accuracy is enough. For the case study presented in this work, $R^{2}$ is above 0.85 for RCM CCLM4-8-17 nested to CNRM-CM5 and 0.67 for WRF331F nested to IPSL-CM5A$M R$ in the case of $P$. In the case of $T$, these values are 0.70 and 0.75 , respectively. Figure 4 shows the historical data and the individual projections obtained for $P$ and $T$ for the considered case study. The average monthly results for the mean year have been represented in Figure 5.

The generated scenarios can be used as individual local projections or create ensembles of them that could produce more robust climate scenarios than those based on a single projection [23]. The subroutine ensen.exe allows to generate four ensembles of individual projections. Two of them are defined by combining, as equifeasible members, all the individual projections generated by applying delta change or bias correction approaches (see Figure 2). Two other options are defined by combining only the noneliminated projections in the multiobjective analysis for the two approaches (delta change and bias correction). The tool allows performance of the multiobjective analyses by considering only basic statistics (mean, standard deviation, and asymmetry coefficient) or including also drought statistics (duration, magnitude, and intensity). The drought statistics are calculated by applying the Run Theory to the corresponding SPI monthly series $[12,32]$. The drought statistics series are calculated considering different thresholds of SPI values (it covers the whole range of negative values of SPI obtained) to define drought periods. In the calculation of the SPI, the probability of occurrence of $P$ in the RCM simulations was obtained by using the parameters calibrated from the historical series to perform an appropriate comparison [12]. In this analysis, an RCM or a combination of RCM and correction technique is eliminated (dominated solution in multiobjective terminology), if another projection has a better fit to the historical data for all the statistics. The index employed to measure the goodness of fit is the mean of the quadratic difference between simulations and historical 


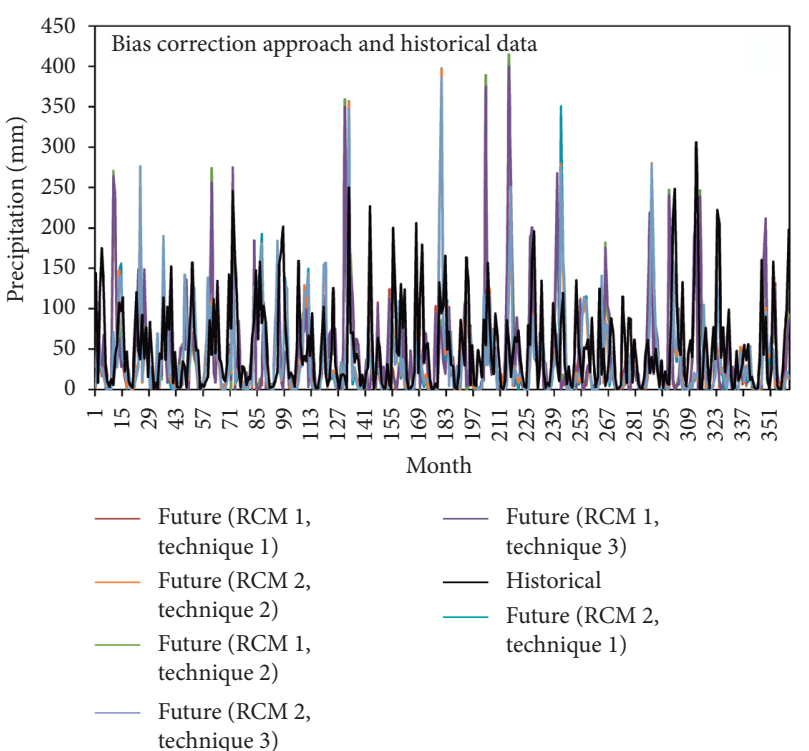

(a)

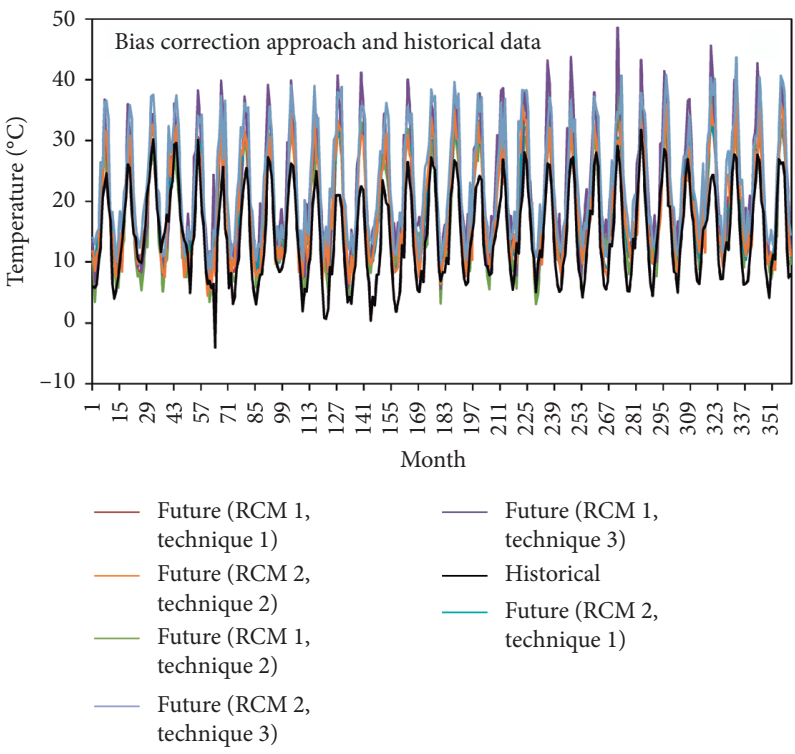

(c)

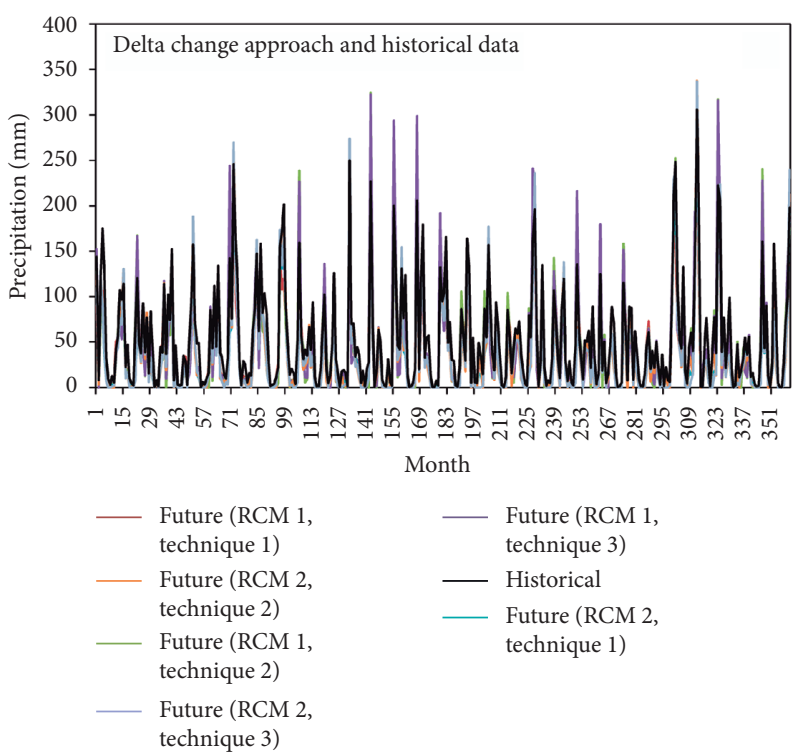

(b)

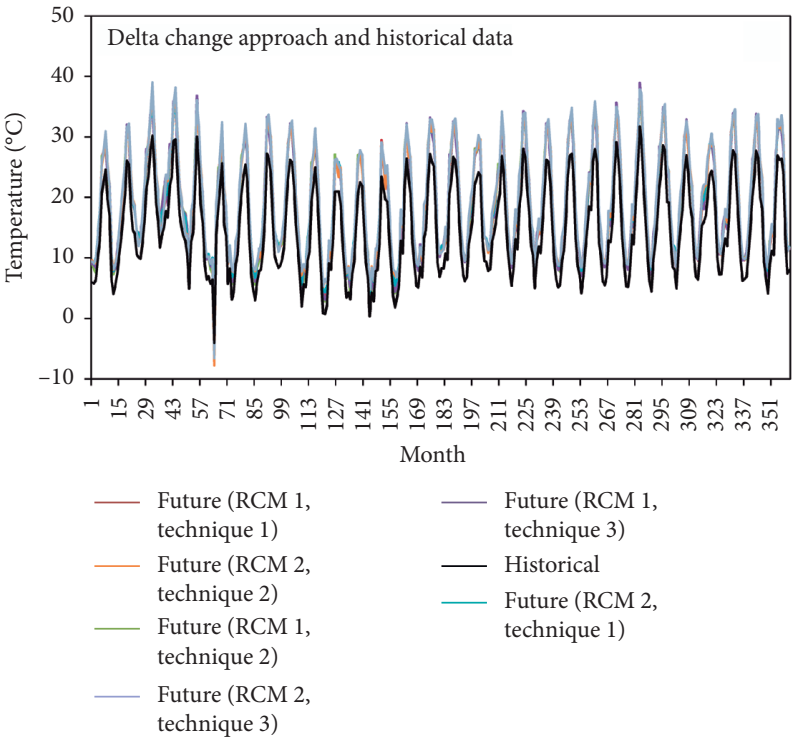

(d)

Figure 4: Historical data and individual projections of $P$ using the (a) bias correction approach and (b) delta change approach and of Tusing the (c) bias correction approach and (d) delta change approach generated by using the GROUNDS tool.

series divided by the square of the mean historical value for each statistic. This index is applied to each considered statistic. The tool also includes a threshold (it can be modified by the user) that allows us to define when an approach is considered significantly better than others with respect to a specific statistic. This threshold, measured in percentage of relative difference, allows us to assume that certain differences in some statistics are not significant. For the considered example, this threshold has been considered $3 \%$. The subroutine ensen.exe also generates the files dominated.txt and statistics.txt. The first indicates the combinations of RCMs and techniques (in the case of bias correction approach) and RCMs (in the case of delta change approach) that are dominated solutions. These solutions are eliminated to obtain the non-equifeasible ensembles. The second file includes the values of the indices used for the multiobjective analysis. For the case study, the combination of the second RCM (WRF331F nested to IPSL-CM5A-MR) and the first correction technique (first moment correction) was identified as dominated solution. The mean values of $P$ and $T$ obtained with the ensembles and their standard deviations for the case study are represented in Figure 6. In the case of delta change, the equifeasible and the multiobjective ensembles are equivalent because there is no dominated solution attending to the two RCMs considered. For the case study, an important reduction in $P$ (mean of the four ensembles of $23.7 \%$ ) and increase in $T$ (mean of the four ensembles of $32.6 \%$ ) are obtained. With respect to the 

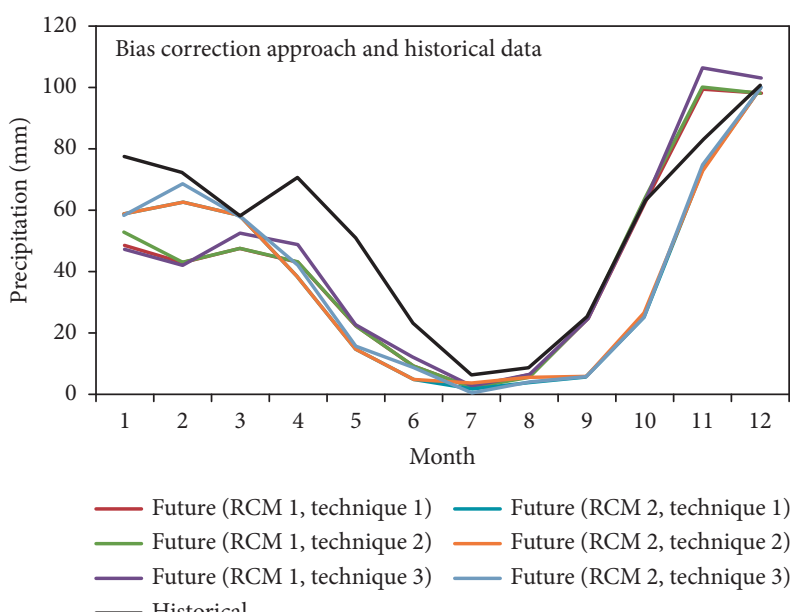

(a)

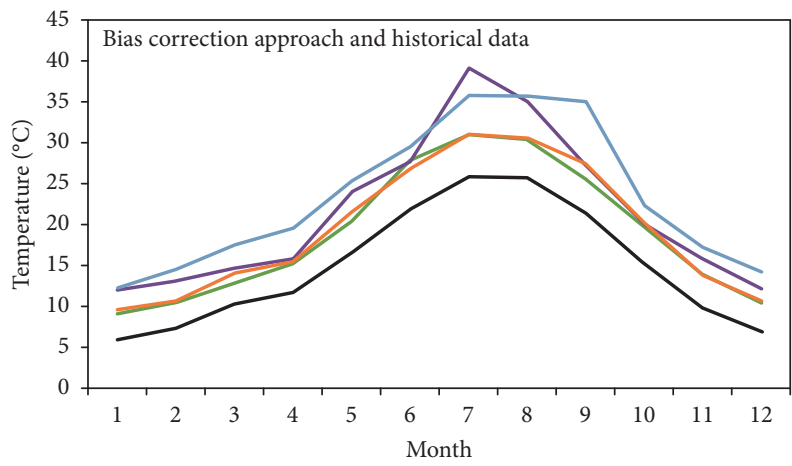

$\begin{array}{ll}\text { Future (RCM 1, technique 2) } & \text { Future (RCM 2, technique 2) } \\ \text { Future (RCM 1, technique 3) } & \text { Future (RCM 2, technique 3) } \\ \text { Historical } & \end{array}$

(c)

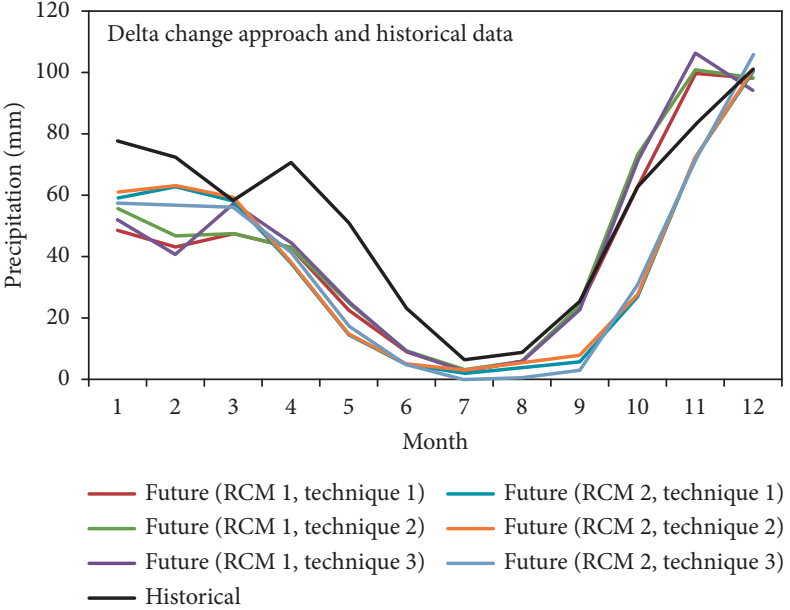

(b)

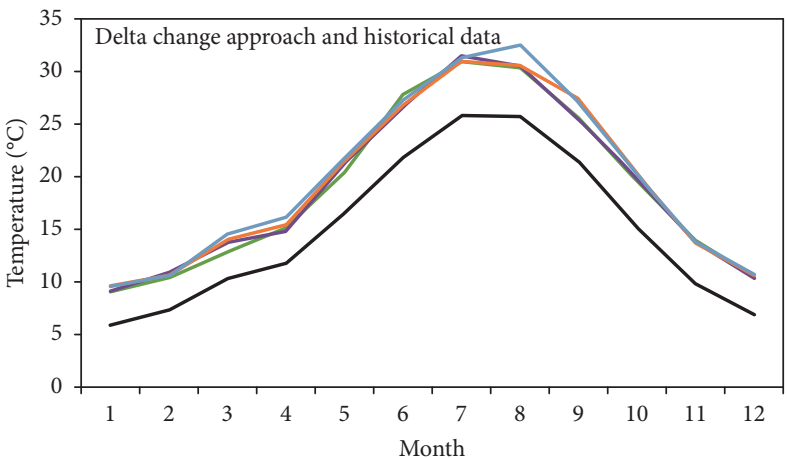

— Future (RCM 1, technique 2) — Future (RCM 2, technique 2)

— Future (RCM 1, technique 3) — Future (RCM 2, technique 3)

(d)

FIGURE 5: Mean year at monthly scale for the historical data and individual projections of $P$ using the (a) bias correction approach and (b) delta change approach and of $T$ using the (c) bias correction approach and (d) delta change approach generated by using the GROUNDS tool.

standard deviation, in the case of $P$, the ensembles show a lower value with the exception of the autumn where some ensembles predict an increment of the variability. In the case of the temperature, the bias correction approaches predict a lower variability and the delta change approaches a higher variability.

Finally, the tool also allows calculating historical and future ETP series by means of the subroutine ETP.exe. This subroutine employs the Hargreaves method [33, 34] and requires as inputs the historical and the future ensembles (or individual projections) of maximum and minimum $T$ and the latitude of each location or station considered. The tool employs the modified method proposed by Samani [35]. This method uses tabulated values (depending on the latitude) to calculate solar radiation. It is also needed to indicate if the study area is located in a coastal or noncoastal zone to determine an empirical coefficient, which should be different for interior regions and for coastal regions [36]. The mean historical and future ETP for the case study have been represented in Figure 7. The mean increment of the four future ensembles of ETP with respect to the historical data is $31.8 \%$.

\section{Utility and Discussion}

The GROUNDS tool allows correcting the future climatic simulations using the observed series to reduce the uncertainties of the RCMs. The tool requires complete monthly series (without gaps) and an adequate assessment of the quality in order to ensure that they represent the climatology of the case study. These corrected projections are plausible scenarios that intend to be representative of a period or a mean increment of $T$ (local or global warming). The IPCC in some of its latest reports opts for using a mean increment of global warming to better reach users and decision makers (e.g., [37]). Some research works included this approach too $[38,39]$. Multiple future series could be generated for the same climatic conditions. The stochastic weather generators (SWG) provide multiple synthetic time series of weather data for a location or multiple locations based on the statistical characteristics of the observed climate at these locations $[40,41]$. A large amount of works employed SWG to assess the impact of CC $[42,43]$. The tool presented in this work could be combined with a SWG to generate multiple 

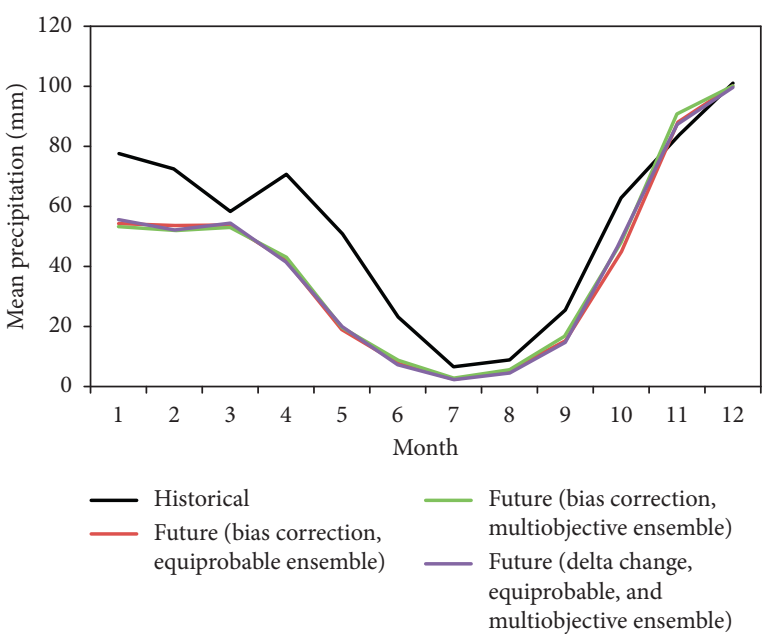

(a)

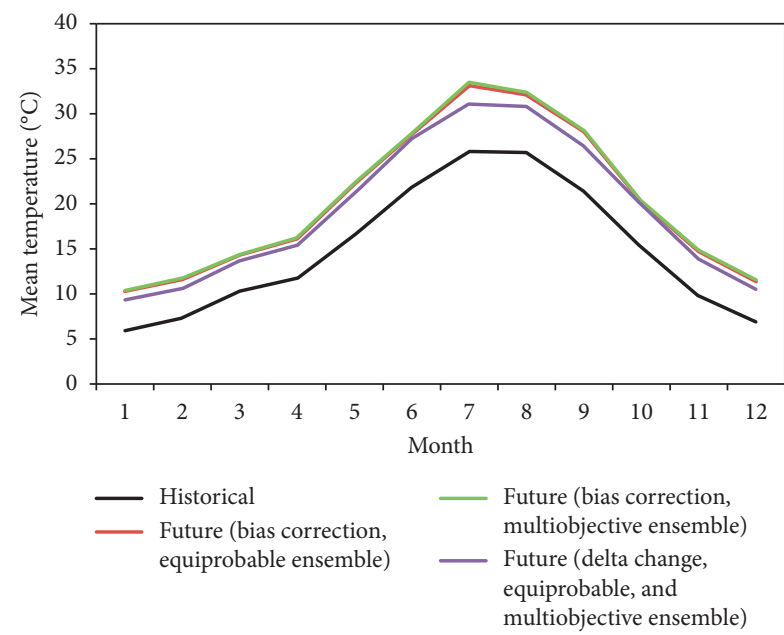

(c)

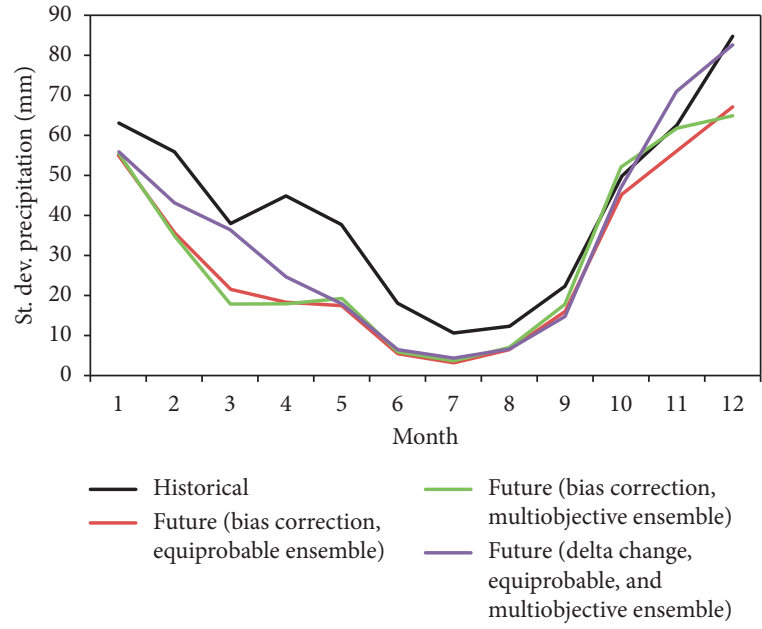

(b)

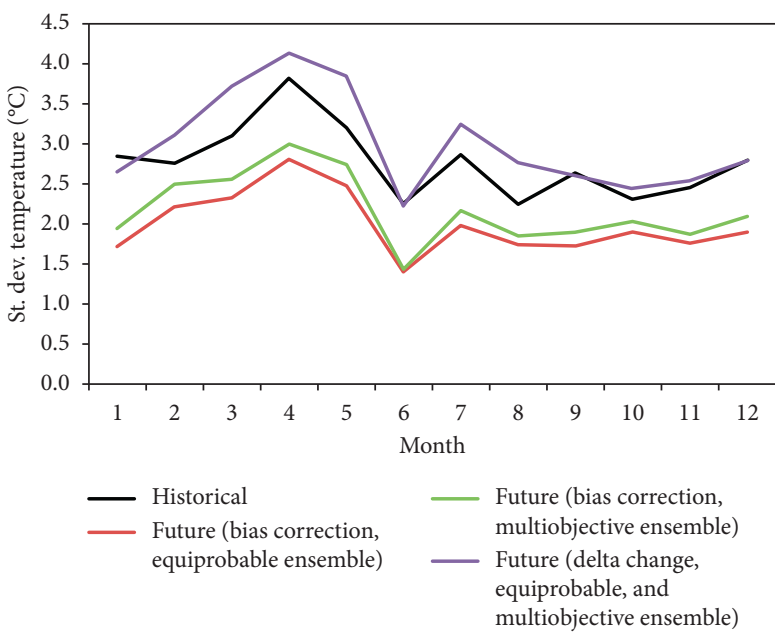

(d)

Figure 6: Mean year at monthly scale for the historical data and future ensembles of (a), (b) $P$ and its standard deviation and (c), (d) $T$ and its standard deviation generated by using the GROUNDS tool for the case study. Note that for the example considered in the case of the delta change approach, the multiobjective ensembles are equivalent to the equifeasible ensembles because there is not any dominated solution.

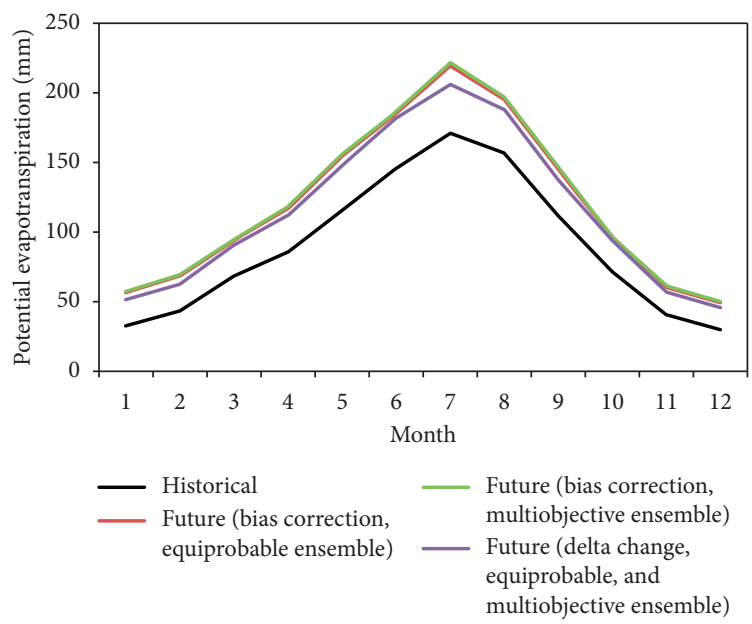

FIgURE 7: Mean year at monthly scale for the historical and future ensembles of ETP generated by using the GROUNDS tool for the case study. Note that for the example considered in the case of the delta change approach, the multiobjective ensembles are equivalent to the equifeasible ensembles because there is not any dominated solution. 
series of potential future local scenarios of CC which could feed hydrological models quantifying the uncertainty of the projections through a Monte Carlo analysis [44, 45].

As pointed in the Introduction section, one of the main advantages of the GROUNDS tool is its applicability to different cases studies. In recent years, two subroutines of the tool (inpro.exe and ensen.exe) have been employed to generate potential scenarios for assessing CC impacts in different typologies of WR systems. It has been tested in cases covering different spatial scales: country [26], basin [12], aquifer [14, 46, 47], and mountain range [16, 48]. Furthermore, the local scenarios of CC generated by using the GROUNDS tool have been propagated to different variables in different case studies: recharge $[16,26]$, ground subsidence [47], and snow cover area [48]. The tool has been proven to be effective for hydrological applications and could contribute to the analyses to support decision-making processes by experts or public participation $[49,50]$.

All the cited applications correspond to case studies located in Spain, where important reduction in $P$ and increment in $T$ are expected due to CC. The tool also allows quantifying the change in variability of the climatic variables at seasonal and monthly scale. This variability in general will be higher due to CC $[51,52]$. For the case showed in this study, the tool predicts a higher variability of $P$ in autumn. In the case of $T$, the delta change ensembles show higher variability than the historical data (see Figure 6).

We have developed a general tool that uses several correction techniques (first moment correction, first and second moment correction, and linear regression). It does not include correction techniques based on the cumulative distribution function, which have been employed by other authors with good results $[53,54]$. However, the differences between these techniques and more simple techniques, as first and second moment corrections, are not significant for the hydrological applications where we have tested them [12]. On the other hand, the tool employs and generates monthly series. This could be an inconvenience for some hydrological applications that use daily data [55-57]. The possibility of generating daily data was tested, but if the second moment correction is applied, it might generate negative values of $P$. If these values are moved to zero, the statistics of the series can suffer modifications and the information from RCMs can be altered [31]. However, the monthly series can be transformed to daily series using the daily pattern of distribution of the monthly historical values to distribute the generated future monthly values [48].

On the other hand, the local future scenarios can be propagated through appropriate hydrological models to study the impacts on other variables (e.g., aquifer recharge or discharge [26], chloride concentration in coastal aquifers [46], streamflow, snow cover area, and snow depth [48]). They can be even propagated with other models to assess nonhydrological physical variables (e.g., subsidence [47]).

\section{Conclusions}

In this work, the new tool GROUNDS, which generates potential future local scenarios of CC, has been presented.
The tool is applicable to any case study and requires historical and RCM simulation information to generate individual local projections. The generated future scenarios can be used as individual local projections or create ensembles of them that could produce more robust climate scenarios taking into account basic and droughts statistics. The tool also allows determination of the future simulation period from a specific increment in mean $T$ (local warming scenario) and propagation the impacts on $T$ to ETP.

For the case study (located in south Spain) used to illustrate the functionalities of the tool, an important reduction in $P$ (in mean 23.7\%) and an increment in Tand ETP (in mean $32.6 \%$ and $31.8 \%$, respectively) have been obtained.

Two subroutines of the tool have proven to be effective for different scales of application and spatiotemporal resolutions in previous works (see the previous section). The tool can be also combined with appropriate hydrological models to propagate impacts of CC to other hydrological variables or SWG to assess the uncertainty of the generated future scenarios in these models.

\section{Data Availability}

The historical data and the RCM simulations used to support the findings of this study come from previously reported studies and datasets, which have been cited. The software developed in this study may be available for research purposes upon request from the corresponding author.

\section{Conflicts of Interest}

The authors declare that there are no conflicts of interest regarding the publication of this paper.

\section{Acknowledgments}

This research was partially supported by the research projects SIGLO-AN (RTI2018-101397-B-I00) from the Spanish Ministry of Science, Innovation and Universities (Programa Estatal de I+D+I Orientada a los Retos de la Sociedad) and the GeoE.171.008-TACTIC Project from the GeoERA Organization funded by the European Union's Horizon 2020 Research and Innovation Program.

\section{References}

[1] A. K. Misra, "Climate change and challenges of water and food security," International Journal of Sustainable Built Environment, vol. 3, no. 1, pp. 153-165, 2014.

[2] W. Cramer, J. Guiot, M. Fader et al., "Climate change and interconnected risks to sustainable development in the Mediterranean," Nature Climate Change, vol. 8, no. 11, pp. 972-980, 2018

[3] IPCC, Climate Change 2014: Synthesis Report. Contribution of Working Groups I, II and III to the Fifth Assessment Report of the Intergovernmental Panel on Climate Change, R. K. Pachauri and L. A. Meyer, Eds., p. 151, IPCC, Geneva, Switzerland, 2014.

[4] J. S. Dryzek, R. B. Norgaard, and D. Schlosberg, "Climate change and society: approaches and responses," in The Oxford Handbook of Climate Change and Society, S. Dryzek John and 
S. David, Eds., pp. 490-503, Oxford University Press, Oxford, UK, 2011.

[5] IPCC, Managing the Risks of Extreme Events and Disasters to Advance Climate Change Adaptation. A Special Report of Working Groups I and II of the Intergovernmental Panel on Climate Change, C. B. Field, V. Barros, T. F. Stocker et al., Eds., p. 582, Cambridge University Press, Cambridge, UK, 2012.

[6] CORDEX Project, "The coordinated regional climate downscaling experiment CORDEX. Program sponsored by World climate research program (WCRP)," 2013, http://www. cordex.org/.

[7] P. Jacques, "Downscaling climate models and environmental policy: from global to regional politics," Journal of Environmental Planning and Management, vol. 49, no. 2, pp. 301-307, 2006.

[8] I. M. Picketts, S. J. Déry, and J. A. Curry, "Incorporating climate change adaptation into local plans," Journal of Environmental Planning and Management, vol. 57, no. 7, pp. 984-1002, 2014.

[9] I. M. Held and B. J. Soden, "Robust responses of the hydrological cycle to global warming," Journal of Climate, vol. 19, no. 21, pp. 5686-5699, 2006.

[10] P. Wu, N. Christidis, and P. Stott, "Anthropogenic impact on Earth's hydrological cycle," Nature Climate Change, vol. 3, no. 9, pp. 807-810, 2013.

[11] M. Safeeq and A. Fares, "Hydrologic response of a Hawaiian watershed to future climate change scenarios," Hydrological Processes, vol. 26, no. 18, pp. 2745-2764, 2012.

[12] A.-J. Collados-Lara, D. Pulido-Velazquez, and E. PardoIgúzquiza, "An integrated statistical method to generate potential future climate scenarios to analyse droughts," Water, vol. 10, no. 9, p. 1224, 2018.

[13] T. Y. Stigter, J. P. Nunes, B. Pisani et al., "Comparative assessment of climate change and its impacts on three coastal aquifers in the Mediterranean," Regional Environmental Change, vol. 14, no. S1, pp. 41-56, 2014.

[14] L. Baena-Ruiz, D. Pulido-Velazquez, A.-J. Collados-Lara et al., "Summarizing the impacts of future potential global change scenarios on seawater intrusion at the aquifer scale," Environmental Earth Sciences, vol. 79, no. 5, p. 99, 2020.

[15] N. Salzmann, J. Nötzli, C. Hauck, S. Gruber, M. Hoelzle, and W. Haeberli, "Ground surface temperature scenarios in complex high-mountain topography based on regional climate model results," Journal of Geophysical Research, vol. 112, no. F2, 2007.

[16] E. Pardo-Igúzquiza, A. J. Collados-Lara, and D. PulidoVelazquez, "Potential future impact of climate change on recharge in the Sierra de las Nieves (southern Spain) highrelief karst aquifer using regional climate models and statistical corrections," Environmental Earth Sciences, vol. 78, no. 20 , p. $598,2019$.

[17] M. Déqué, D. P. Rowell, D. Lüthi et al., “An intercomparison of regional climate simulations for Europe: assessing uncertainties in model projections," Climatic Change, vol. 81, no. S1, pp. 53-70, 2007.

[18] C. Dobler, S. Hagemann, R. L. Wilby, and J. Stötter, "Quantifying different sources of uncertainty in hydrological projections in an Alpine watershed," Hydrology and Earth System Sciences, vol. 16, no. 11, pp. 4343-4360, 2012.

[19] J. Chen, F. P. Brissette, D. Chaumont, and M. Braun, "Finding appropriate bias correction methods in downscaling precipitation for hydrologic impact studies over North America," Water Resources Research, vol. 49, no. 7, pp. 4187-4205, 2013.
[20] M. Luo, T. Liu, F. Meng et al., "Comparing bias correction methods used in downscaling precipitation and temperature from regional climate models: a case study from the kaidu river basin in western China," Water, vol. 10, no. 8, p. 1046, 2018.

[21] S. Watanabe, S. Kanae, S. Seto, P. J.-F. Yeh, Y. Hirabayashi, and T. Oki, "Intercomparison of bias-correction methods for monthly temperature and precipitation simulated by multiple climate models," Journal of Geophysical Research: Atmospheres, vol. 117, no. D23, 2012.

[22] J. Räisänen and O. Räty, "Projections of daily mean temperature variability in the future: cross-validation tests with ENSEMBLES regional climate simulations," Climate Dynamics, vol. 41, no. 5-6, pp. 1553-1568, 2013.

[23] AEMET (Spanish Meteorologial Agency), Generación de Escenarios Regionalizados de Cambio Climático Para España, Agencia Estatal de Meteorología (Ministerio de Medio Ambiente y Medio Rural y Marino), Madrid, Spain, 2009.

[24] L. Gudmundsson, "Statistical transformations for post-processing climate model output," 2016, https://cran.r-project. org/web/packages/qmap/qmap.pdf.

[25] H. Rathjens, B. Bieger, S. Srinivasan, I. Chaubey, and J. G. Arnold, "CMhyd user manual," 2016, http://swat.tamu. edu/software/cmhyd/.

[26] D. Pulido-Velazquez, A.-J. Collados-Lara, and F. J. Alcalá, "Assessing impacts of future potential climate change scenarios on aquifer recharge in continental Spain," Journal of Hydrology, vol. 567, pp. 803-819, 2018.

[27] D. Pulido-Velazquez, L. Garrote, J. Andreu, F.-J. MartinCarrasco, and A. Iglesias, "A methodology to diagnose the effect of climate change and to identify adaptive strategies to reduce its impacts in conjunctive-use systems at basin scale," Journal of Hydrology, vol. 405, no. 1-2, pp. 110-122, 2011.

[28] S. Herrera, J. Fernández, and J. M. Gutiérrez, "Update of the Spain02 gridded observational dataset for euro-CORDEX evaluation: assessing the effect of the interpolation methodology," International Journal of Climatology, vol. 36, no. 2, pp. 900-908, 2016.

[29] C. Piani, J. O. Haerter, and E. Coppola, "Statistical bias correction for daily precipitation in regional climate models over Europe," Theoretical and Applied Climatology, vol. 99, no. 1-2, pp. 187-192, 2010.

[30] L. P. Seaby, J. C. Refsgaard, T. O. Sonnenborg, and A. L. Højberg, "Spatial uncertainty in bias corrected climate change projections and hydrogeological impacts," Hydrological Processes, vol. 29, no. 20, pp. 4514-4532, 2015.

[31] D. Pulido-Velazquez, J. L. García-Aróstegui, J.-L. Molina, and M. Pulido-Velázquez, "Assessment of future groundwater recharge in semi-arid regions under climate change scenarios (Serral-Salinas aquifer, SE Spain). Could increased rainfall variability increase the recharge rate?" Hydrological Processes, vol. 29, no. 6, pp. 828-844, 2015.

[32] S. Khan, H. F. Gabriel, and T. Rana, "Standard precipitation index to track drought and assess impact of rainfall on watertables in irrigation areas," Irrigation and Drainage Systems, vol. 22, no. 2, pp. 159-177, 2008.

[33] G. H. Hargreaves and Z. A. Samani, "Reference crop evapotranspiration from temperature," Applied Engineering in Agriculture, vol. 1, no. 2, pp. 96-99, 1985.

[34] R. G. Allen, L. S. Pereira, and D. Raes y Smith, "Crop evapotranspiration-guidelines for computing crop water requirements-FAO irrigation and drainage paper 56," 1998, http://www.fao.org/docrep/X0490E/X0490E00.htm\#Contents. 
[35] Z. Samani, "Estimating solar radiation and evapotranspiration using minimum climatological data," Journal of Irrigation and Drainage Engineering, vol. 126, no. 4, pp. 265-267, 2000.

[36] G. H. Hargreaves, Simplified Coefficients for Estimating Monthly Solar Radiation in North America and Europe, Utah State University, Logan, UT, USA, 1994.

[37] IPCC, "Summary for policymakers. In: global warming of $1.5^{\circ} \mathrm{C}$. An IPCC special report on the impacts of global warming of $1.5^{\circ} \mathrm{C}$ above pre-industrial levels and related global greenhouse gas emission pathways," in The Context of Strengthening the Global Response to the Threat of Climate Change, Sustainable Development, and Efforts to Eradicate Poverty, P. Zhai, H.-O. Pörtner, D. Roberts et al., Eds., p. 32, World Meteorological Organization, Geneva, Switzerland, 2018.

[38] A. D. King, D. J. Karoly, and B. J. Henley, "Australian climate extremes at $1.5^{\circ} \mathrm{C}$ and $2^{\circ} \mathrm{C}$ of global warming," Nature Climate Change, vol. 7, no. 6, pp. 412-416, 2017.

[39] J. Wu, Z. Han, Y. Xu, B. Zhou, and X. Gao, "Changes in extreme climate events in China under $1.5^{\circ} \mathrm{C}-4^{\circ} \mathrm{C}$ global warming targets: projections using an ensemble of regional climate model simulations," Journal of Geophysical Research: Atmospheres, vol. 125, Article ID e2019JD031057, 2020.

[40] D. S. Wilks and R. L. Wilby, "The weather generation game: a review of stochastic weather models," Progress in Physical Geography: Earth and Environment, vol. 23, no. 3, pp. 329357, 1999.

[41] N. Peleg, S. Fatichi, A. Paschalis, P. Molnar, and P. Burlando, "An advanced stochastic weather generator for simulating 2D high-resolution climate variables," Journal of Advances in Modeling Earth Systems, vol. 9, no. 3, pp. 1595-1627, 2017.

[42] M. A. Semenov and E. M. Barrow, "Use of a stochastic weather generator in the development of climate change scenarios," Climatic Change, vol. 35, no. 4, pp. 397-414, 1997.

[43] J. Chen, H. Chen, and S. Guo, "Multi-site precipitation downscaling using a stochastic weather generator," Climate Dynamics, vol. 50, no. 5-6, pp. 1975-1992, 2018.

[44] R.-S. Blasone, H. Madsen, and D. Rosbjerg, "Uncertainty assessment of integrated distributed hydrological models using GLUE with Markov chain Monte Carlo sampling," Journal of Hydrology, vol. 353, no. 1-2, pp. 18-32, 2008.

[45] H. K. McMillan, I. K. Westerberg, and T. Krueger, "Hydrological data uncertainty and its implications," WIREs Water, vol. 5, no. 6, Article ID e1319, 2018.

[46] D. Pulido-Velazquez, A. Renau-Pruñonosa, C. Llopis-Albert et al., "Integrated assessment of future potential global change scenarios and their hydrological impacts in coastal aquifers-a new tool to analyse management alternatives in the Plana Oropesa-Torreblanca aquifer," Hydrology and Earth System Sciences, vol. 22, no. 5, pp. 3053-3074, 2018.

[47] A.-J. Collados-Lara, D. Pulido-Velazquez, R. M. Mateos, and P. Ezquerro, "Potential impacts of future climate change scenarios on ground subsidence," Water, vol. 12, no. 1, p. 219, 2020.

[48] A.-J. Collados-Lara, E. Pardo-Igúzquiza, and D. PulidoVelazquez, "A distributed cellular automata model to simulate potential future impacts of climate change on snow cover area," Advances in Water Resources, vol. 124, pp. 106-119, 2019.

[49] H. Macian-Sorribes and M. Pulido-Velazquez, "Integrating historical operating decisions and expert criteria into a DSS for the management of a multireservoir system," Journal of Water Resources Planning and Management, vol. 143, no. 1, 2017.
[50] C. Llopis-Albert, J. M. Merigó, H. Liao, Y. Xu, J. GrimaOlmedo, and C. Grima-Olmedo, "Water policies and conflict resolution of public participation decision-making processes using prioritized ordered weighted averaging (OWA) operators," Water Resources Management, vol. 32, no. 2, pp. 497-510, 2018.

[51] A. G. Pendergrass, R. Knutti, F. Lehner, C. Deser, and B. M. Sanderson, "Precipitation variability increases in a warmer climate," Scientific Reports, vol. 7, no. 1, p. 17966, 2017.

[52] F. J. M. M. Nijsse, P. M. Cox, C. Huntingford, and M. S. Williamson, "Decadal global temperature variability increases strongly with climate sensitivity," Nature Climate Change, vol. 9, no. 8, pp. 598-601, 2019.

[53] L. Gudmundsson, J. B. Bremnes, J. E. Haugen, and T. EngenSkaugen, "Technical Note: downscaling RCM precipitation to the station scale using statistical transformations \&ndash; a comparison of methods," Hydrology and Earth System Sciences, vol. 16, no. 9, pp. 3383-3390, 2012.

[54] L. Sangelantoni, A. Russo, and F. Gennaretti, "Impact of bias correction and downscaling through quantile mapping on simulated climate change signal: a case study over Central Italy," Theoretical and Applied Climatology, vol. 135, no. 1-2, pp. 725-740, 2019.

[55] Y. Huang, A. Bárdossy, and K. Zhang, "Sensitivity of hydrological models to temporal and spatial resolutions of rainfall data," Hydrology and Earth System Sciences, vol. 23, no. 6, pp. 2647-2663, 2019.

[56] J. Senent-Aparicio, S. Liu, J. Pérez-Sánchez, A. López-Ballesteros, and P. Jimeno-Sáez, "Assessing impacts of climate variability and reforestation activities on water resources in the headwaters of the segura river basin (SE Spain)," Sustainability, vol. 10, no. 9, p. 3277, 2018.

[57] H. Moutahir, M. Fernández-Mejuto, J. M. Andreu et al., "Observed and projected changes on aquifer recharge in a Mediterranean semi-arid area, SE Spain," Environmental Earth Sciences, vol. 78, p. 671, 2019. 